\title{
Structuring a System Dynamics Model using Group Model Building: Case Study on Flight Test Human Resources
}

\author{
Alvimar de Lucena Costa Junior \\ Instituto Tecnológico de Aeronáutica \\ São José dos Campos, São Paulo, Brazil \\ lucenaalcj@ita.br
}

\author{
Mischel Carmen Neyra Belderrain \\ Instituto Tecnológico de Aeronáutica \\ São José dos Campos, São Paulo, Brazil \\ carmen@ita.br
}

\begin{abstract}
This paper summarizes a master's degree Dissertation that presents a method that allows capture and organize mental models of all levels of Stakeholders to draw a System Dynamics Model closer to reality and more effective on Strategy proposition. This is done through information raised applying Group Model Building (GMB), and using PSM specific tools, like Mental Maps and Cognitive Maps. All these tools allow merge opinions and elicitate knowledge from stakeholders involved on the process. To demonstrate the method's suitability, it was applied to a Case Study to develop a System Dynamics Model for the Flight Test Specialized Human Resources Career Flow. The method has five stages: first, recognize the Messy Situation; second, identify process Stakeholders; third, conduct Workshops and interviews applying Cognitive Maps and, then, GMB; forth, build collective maps presenting a collective point of view for all parts; fifth, build a System Dynamics Model effective and recognizable for all involved Stakeholders, ready to be used as a tool to Strategy proposition to solve the Messy Situation. Flight Test Specialized Human Resources Case Study results show both the model's effectiveness and stakeholder commitment, based on the proposed method, proving its adequacy.
\end{abstract}

Keywords- System Dynamics; Group Model Building; Problem Structuring Methods; Cognitive Maps

\section{Introduction}

System Dynamics (SD) has been producing models and simulations for more than sixty years since Forrester [1] first publication on the issue. Nowadays, SD is recognized as a method to describe, model, simulate and dynamically analyze complex problems and systems, over processes, information, organizational frontiers, and strategies. SD allows investigation on industrial, social, environmental and geopolitical systems.

Problem Structuring Methods (PSM) begun its delimitation during the 1980s, and its first formal mention was on the 1989 edition of Rosenhead and Mingers's book "Rational Analysis for a Problematic World: Problem Structuring Methods for Complexity, Uncertainty and Conflict" [2]. It is one of the main branches of the Soft Operational Research, area of Operational Research (OR) named in opposition to Hard OR, more traditional and quantitative based, as poses [16] and [23].
As [2] writes, PSM are characterized by Systems Thinking, and mostly use qualitative models.

Taking advantage of PSM philosophy, Group Model Building was created, connecting both the elicitation capacity of Soft Operational Research approaches, and the System Dynamics formality. This method allows participatory modelling, and its first target is learning, as [3] exposes, improving the target system mental models.

A modeler should wide the one-person Point of View to reach an effective Messy Situation model, allowing a larger and diverse number of stakeholders to contribute to better models. In that matter, Group Model Building corresponds.

As an example of a Messy Situation, the Brazilian Air Force Science and Technological Department (DCTA) faces a large problem on Talent and Knowledge Management, on some Specialized Human Resources (SHR) Career Flow. Flight Test personnel is one of the many key technological staff hit by this problem. 
In that sense, the development of a System Dynamics Model on that SHR Career Flow, based on a GMB approach that could put together points of view of stakeholders from all levels and types, could support DCTA to establish effective SHR Strategies.

The author is himself a Flight Test Engineer since 2011 and have been Flight Test Division Head for Flight Test and Research Institute (IPEV), being able to use his own experience and knowledge to contribute with the intended results.

\section{Literature Review}

\subsection{Problem Structuring Methods (PSM)}

During the 70`s, Operational Researchers get to know that the optimization and quantification view of traditional Operational Research, when working on Messy Situations, inevitably reached the need to select the most important variables for the model. This judgment of which variable was of interest, was, also inevitably, subjective to the researcher. That was classified as the OR Crisis both by [16] and by [2].

Because of that problem, Soft OR (in opposition to Hard OR) was created, proposing Problem Structuring Methods, Qualitative Models, and an environment where the OR researcher was a facilitator for the structuring of the problem, not an instant expert on the process to be modeled.

According to [17] and [16], one of the main PSM is Strategic Options Development and Analysis (SODA). Under SODA, we will focus on one of SODA tools, the Cognitive Maps.

\subsection{PSM: Cognitive Maps}

According to [12], “Cognitive Maps (CogMaps) is a technique which has been developed over a period and through its application has demonstrated its use for Operational Researchers working on a variety of different tasks.

CogMaps help structuring Messy or Complex Situations, assisting the interview process by increasing understanding and generating agendas, and managing large amounts of qualitative data" from people's understanding and from documents.

CogMaps technique is based on George Kelly's theory of personal constructs [18], and has its principles grounded on this theory.

Although it's a SODA tool, it may be used singly as a precursor to other structuring methods with great results. An interview could be initially conducted over a CogMap, so the interviewed would have the opportunity to see his ideas on a personal construct way, connecting to each other and generating new insights and connections, allowing a wider understanding of the problem to use a more complex PSM, like Group Model Building or SODA itself.

\subsection{System Dynamics}

According to [2], System Dynamics was developed during the 1950's, by J. Forrester [19], first named Industrial Dynamics. According to Lane [20], in 1956, Forrester, that was working on radar and cannon servos during the Second World War, left the computer development and opened a System Dynamics Model at Sloan School of Management (MIT).

As states [21], the world that we know is not the real world, but the one our senses allow us to reproduce as models in our minds, simplifying them enough to understand it. And, as any model, it does not behave exactly as the real world. The fact that "all models are wrong” [22] is something of deep application on System Dynamics.

A system must consist of three kinds of things: elements, interconnections, and a function or purpose [21]. These interconnections may be physical or information flows, and they keep elements together.

On System Dynamics, the systems are modeled and simulated using Stocks, Flows and variables. In general, variables take place building feedback loops. Causal Loop Diagrams and Feedback Loops are also of central interest on System Dynamics, once most systems have a feedback arm that displaces the common sense.

\subsection{PSM: Group Model Building}

GMB, a method whose development begins in the 1980 s, as [4] reports, brings an approach that seeks to elicit the knowledge of groups of individuals using visual aspects such as mind maps. To do so, GMB takes advantage of the formal elements of the System Dynamics modeling, allowing the group to learn more about the problem throughout the facilitation process, making easier both the exchange of information and the understanding of the results of organizational and procedural changes, by visualizing the mental maps in system dynamics format. Also, CogMaps have similar approach, allowing clarify and organize visually mental models on a standardized way, as teach [12], [11] and [10].

The search for consistency and visual simplicity, as for the equal importance of opinions, is a constant in the works that use GMB, as can be seen in "Scripts for group model building”, by [5], which summarizes much of what was available at this time on procedures to carry out the Group Model Building technique.

In 2002, an analysis of the effectiveness of the method carried out by [6] pointed out, among other results, how GMB was successful in capturing knowledge about a Messy Situation and of the participants' commitment to the proposed solutions. The Systems Dynamics models generated in the work with GMB indicated probable paths to be taken and qualitatively simulated the mental models of the players.

In a more recent literature review on GMB effectiveness, which mentions and retakes [6], [7] note that despite more than 100 GMB methods publications, only a few even attempt quantitative analysis. Although much has changed since the 2002 study, much of the results remain, and GMB is still largely used to 
understand what customers want, to persuade groups, and to discover hidden knowledge.

Thus, although GMB is a PSM based on the use of System Dynamics formal elements, the work published in this area finishes its analysis in the development of Systems Dynamics Mental Maps, with a rather limited quantitative compromise, where one does not properly seek a simulation of a system, but rather the tendencies of certain changes on the organizational or procedural scope, for the better understanding of the problem and its derivations.

The debt of the Group Model Building research to Systems Dynamics, with the advantages of using the GMB for the elaboration of a formal Systems Dynamics Model, have not yet been fully described in the literature.

For all these reasons, this Research will describe a method able to extract and improve the Stakeholders' knowledge using Group Model Building, developing a Systems Dynamics Mental Map that will facilitate both the elaboration of a formal System Dynamics Model (SDM), as well as the appropriation of the strategies suggested by this SDM by the same Stakeholders.

\section{Methodology}

A literature review was conducted during the preparation of the research. The main terms researched on Google Scholar, that forwarded to the main science repository (Science Direct, Elsevier, and others), was System Dynamics, Group Model Building, Cognitive Maps, SODA Maps and combinations. The first filter from this research came to 197 paper published, from 1963 to 2017. None of them indicated an effective use of graphic aids, mental mapping or Group Model Building to support the development of System Dynamics models both dealing with Causal Loop Diagrams and with Quantitative results to support Strategies.

Developed method encompasses five phases of work.

Initially (phase 1), the necessary knowledge is obtained to understand the Messy Situation, through bibliographic research, specialists' discussion or selfknowledge. Afterwards (phase 2), using a small group of Stakeholders and the study of the organizational environment, the Stakeholders of interest on the environment and on the competence under study are identified.

On phase 3, Workshops and Interviews with the Stakeholders are performed, enabling elicitation of information using mental maps, including general cognitive maps, and applying the GMB technique. Several CogMaps and System Dynamics Mental Maps may be developed during that phase.

During phase 4, individual and collective maps are used to obtain an aggregated CogMap and an aggregated Systems Dynamic Mental Map, establishing maps that represented the organization's general knowledge about the Messy Situation. The aggregated CogMap is analyzed in the shadow of its morphological characteristics and under the ideas passed by the constructs. The aggregated Systems Dynamic Mental Map is analyzed in relation to the Causal Loops that it presents, as well as in the
Stakeholders' choices of Stocks, Flows and management variables.

On phase 5, final, the author is able to develop a functional System Dynamics model based on the structuring and better knowledge of the problem and the feedback flows and loops that were unveiled in the previous phases. This allows the study of quantity, stocks and variables of interest trends in the management of the Organization's Messy Situation.

All Stakeholders interviewed may be contacted again, and a complete presentation carried out, as well as the strategies that the Dynamic Systems model revealed, so that these Stakeholders could validate both the final maps and models and the strategies to be employed.

Methodology steps are shown on Fig. 1.

To exemplify an instance of the developed method, the author used a Case Study. In that way, the intermediary products of the System Dynamics Model development, namely, the Aggregated Mental Maps, the Group Model Building Diagrams and the System Dynamics Models itself, eased the understanding of the Flight Tests competency environment and allowing the proposition of strategies within the scope of each manager so that this Flight Test capacity, at least, remains alive in Brazil.

\section{Case Study}

\subsection{Define Messy Situation (Phase 1)}

To define Messy Situation, the author used his own knowledge of the organization and on the historic facts of Flight Test Human Resources in Brazil, as well as bibliographic research on organization's files.

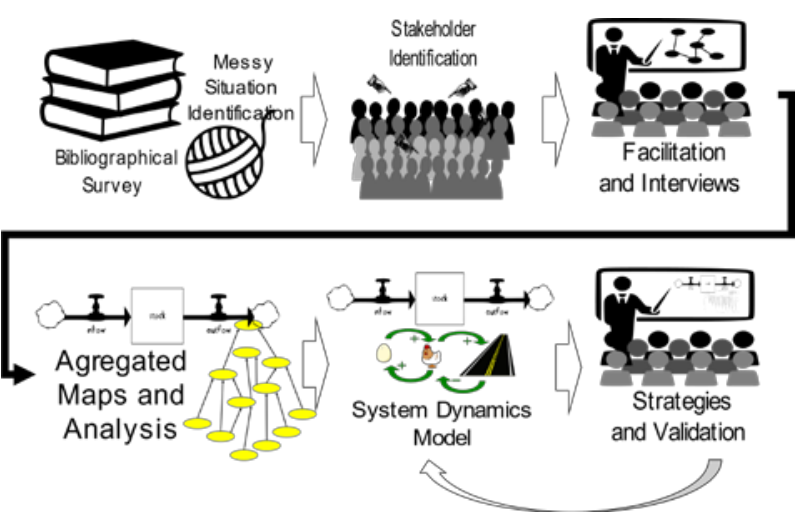

Fig 1. Phases of Case Study

The shortage of qualified personnel on Research and Development (R\&D) in Brazilian Air Force reflects the cuts on the military contingents in the country. The Flight Test and Research Institute (IPEV), as the cradle of Flight Test Personnel formation, suffers too with this shortage, once the raw material for Flight Test School are Fighter Pilots and Aeronautical Engineers, both specialized personnel of interest for the Operational Branch of Air Force, what makes them even rarer for the Science and Development Aeronautical Center (DCTA).

Flight Test Competency is one of the Core Competencies of the Aeronautical Industry in Brazil, what stresses the need it to be preserved [8]. 
On a Systems approach, if Flight Test Career Flow continues to be strangled, new Air Force strategies for Specialized Human Resources are required, so that the organization won't have to deal with the lack of this expertise in the future.

\subsection{Identify and Classify Stakeholders (Phase 2)}

Using [25] definition for Stakeholders and based on discussions with other Flight Test Division members, several Stakeholders of Interest were identified. These Stakeholders were classified according to [9] PowerInterest Grid (Fig. 2), on five groups, derived from three of the four basic groups defined on that paper:

1) SUBJECTS: Flight Test Engineers and Pilots, the Specialized Human resources themselves, that know very well most of the facts of the operational reality on Flight Test activity. Around 24 officers were involved at this discussion (EEV EFEV on Fig. 2);

2) PLAYERS (1): Institute Managers, Director and Vice-Director, that are also Flight Test operatives. They both have the technical knowledge together with some decision level (DIR VDIR on Fig. 2);

3) PLAYERS (2): Department Managers, as Flag Officers and High Managers for DCTA, with high decision level, and high interest on the Flight Test capabilities, that also have to divide their attention on all other Air Force R\&D projects (DCTA and Ass DCTA on Fig. 2). Five Flag Officers from DCTA were interviewed during the research;

4) CONTEXT-SETTLERS (1): Air Force and Defense high Managers under the Defense Ministry and Air Force Command, like Air Force Commander and Defense Minister. Both are very high on decision making, but although his power, pay little attention on the Flight Test subject, diluted on all other Air Force and Defense matters.

5) CONTEXT-SETTLERS (2): Squadron Commanders and other Institute Directors were considered as probable source of information, as clients of Flight Test activities, whether knowingly or not (Cmt ESQD on Fig. 2). Twelve commanding officers participated on the query.

For logistic and opportunity, the CONTEXT SETTLERS (1) were not involved in the Case Study.

The CONTEXT-SETTLERS (2) were involved through questionnaires only, presential and by mail.

Two subgroups of SUBJECTS were defined: the group of TESTERS (16 officers), people that executes Flight Test campaigns and flights, and the group of INSTRUCTORS (eight officers), all personnel involved on formation at Flight Test School.

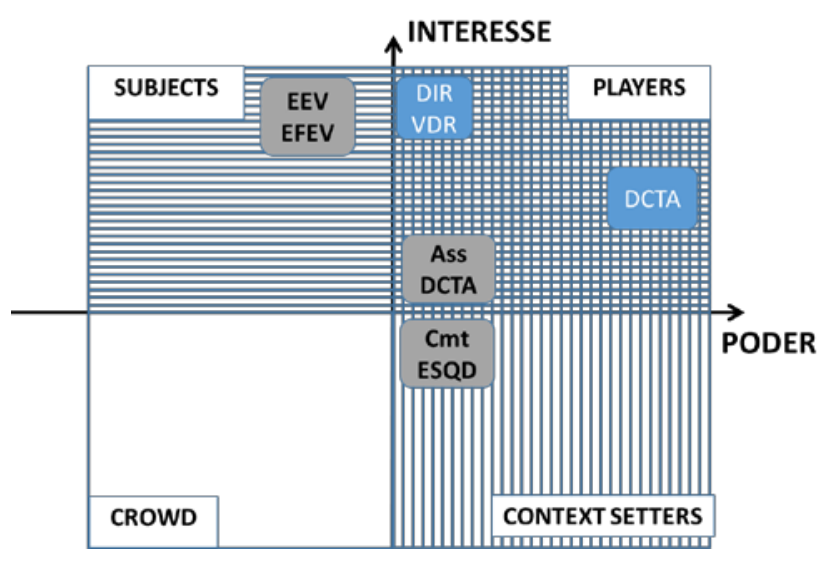

Fig 2. Power x Interest Grid

\subsection{Problem Structuring: Facilitation and Interviews (Phase 3)}

Before phase 3, same CONTEXT-SETTLERS (2) questionnaires were distributed to all stakeholders to wake up on their minds the Messy Situation, like a heating exercise on the subject. Also, questionnaires allowed acquire useful information from CONTEXTSETTLERS (2), about the Flight Test Personnel and activity image.

Using the answers from these questionnaires, and information gathered during phase 1, two Workshops were performed with TESTERS and INSTRUCTORS. Each PLAYER was interviewed individually. Author actuated as Facilitator.

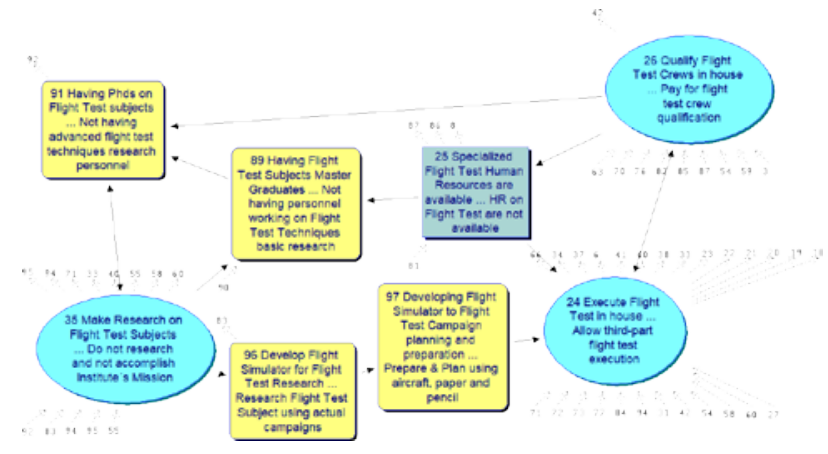

Fig 3. Loop of Constructs

Both Workshops and Interviews were conducted on two steps. First, the Facilitator run mental maps sessions, conducted over the discussions on the previously distributed questionnaire, producing eight collective and individual CogMaps. The second step was GMB sessions conducted with all TESTERS, INSTRUCTORS and PLAYERS, preceded with an express training on Systems Thinking and System Dynamics, and then conducting a debriefing on the CogMap and a list of guiding questions to develop a System Dynamics Mental Map (SDMM) of the Messy Situation. Four different SDMM were developed, one for TESTERS, one for INSTRUCTORS and two for PLAYERS (representing PLAYERS(1) and (2)).

\subsection{Maps Aggregation and Analysis}

The author analyzed all resultant maps, looking for new insights on the target situation. On each collective 
and individual CogMap, loops of constructs were identified, as well as similar constructs.

Dissimilar to regular analysis and treatment gave to CogMaps, as may be found on [10], [15] and [14], construct loops and multiple heads were considered representative for the System Dynamics analysis. Based on the guidance questions for the CogMap development, around the issue "how do you see the flow of information and personnel on Flight Test activity?”, construct loops may give a clue on how some of the ideas covered feedbacks.

Based on this information, an Aggregated CogMap, with 96 constructs, has been drawn, as illustrated on scheme of Fig. 4.

Constructs on light blue corresponds to the three missions of IPEV: Execution, Formation and Research on Flight Testing. Constructs on green are tails, or Strategic Options. The red ones are heads, or Strategic Objectives. The dark blue constructs are centrals, or the ones with most flow of ideas, where most of time and planning should be directed.

During this analysis, 23 Construct Loops were identified, that helped explain and capture the commitment of stakeholders, like the relation between the number of Flight Tests executed and the number of $\mathrm{PhD}$ Specialists graduated, and the great correlation between the number of instructors and the amount of funds available for technological improvements. Example of these loops may be found on Fig. 3.

The four SDMMs were also analyzed and the Stocks and Flows appointed by the Stakeholders helped build an Aggregated SDMM, illustrated on Fig. 5.
The analysis on this Aggregated SDMM involved Causal Loops, preferred Stocks and Flows, and management variables chosen by stakeholders.

All insights gave by these two Aggregated maps were pondered for the next phase.

\subsection{System Dynamics Model}

After all previous considerations, the Author developed a System Dynamics Model (SDM). It has been calibrated using an author's survey on historic data since 1980 for Flight Test Personnel amount and its behavior [24]. Likewise, its Reference Mode [13] was validated by a new debriefing with all Stakeholders. Fig. 6 illustrates final SDM.

Fourteen exogenous variables were identified on the System, from which, based on previous discussions, four Management Variables were detached: Flight Test Course Failing Ratio (CEV), Number of Flight Test PhD Students (PLAMENS), Flight Test Brand Disclosure (Divulga) and Work Conditions (AmbientEV). CEV and PLAMENS are objective variables, based on historic data. Divulga and AmbientEV are subjective variables and oscillates around a $100 \%$ index of perception.

For the variables of interest, Stakeholders chose Technological Sovereign (SOVEREIGN), Number of Monthly executed Flight Test Campaigns (Campaigns) and Flight Test Personnel Total Number (RHEV). Only SOVEREIGN, a subjective variable, had to be expressed by an index, the others are objective variables. Although none are Stocks on the model, all are algebraic result of Stocks, so they have been used to establish a trend. 


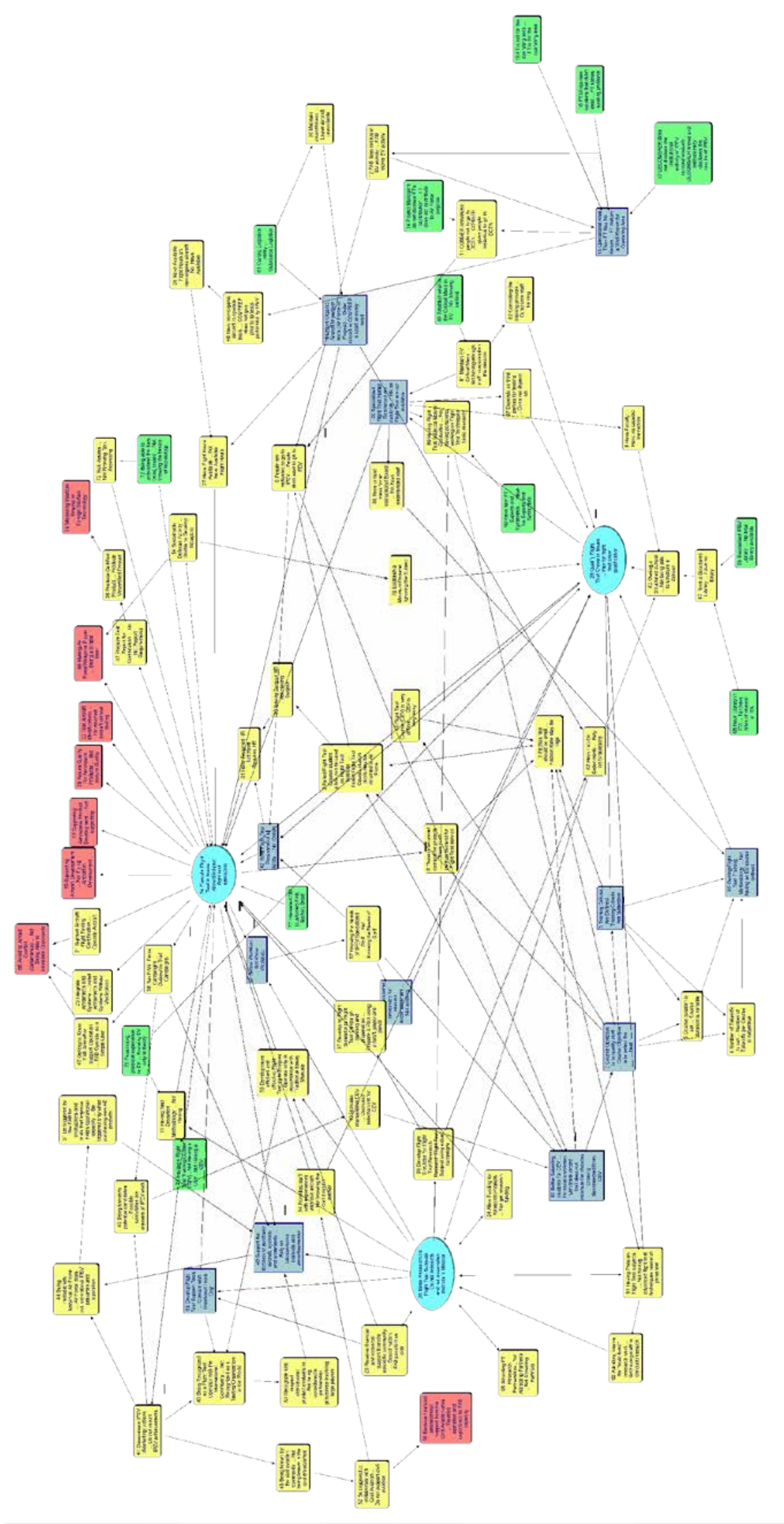

Fig 4. Aggregated CogMap 


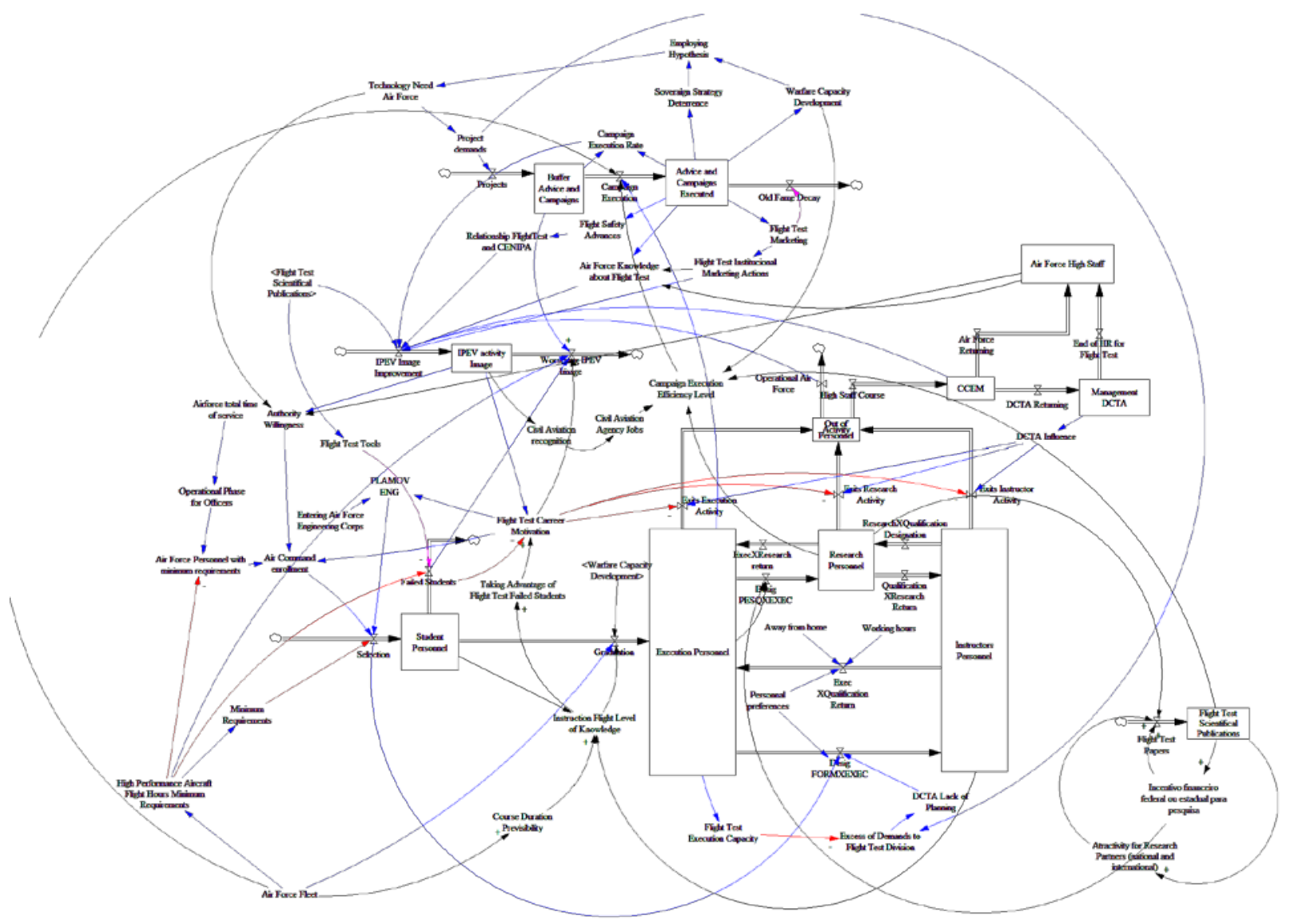

Fig 5. Aggregated SDMM

\subsection{Case Study Conclusions}

Using sensitivity analysis on management variables, and its impact on variables of interest, the model showed that the best strategy was to keep the critical mass of Flight Test Human Resources (RHEV) and good numbers on SOVEREIGN would be improvements on Work Conditions, as can be seen on Fig. 7. This would mostly benefit Flight Test Personnel productivity, increasing the number of executed flight test campaigns and improving Flight Test image on Air Force High Command, that would be more inclined to allow more fighter pilots and engineers to leave operational squadrons and became Flight Test pilots and engineers.

Good results were also noticed investing on Divulga and CEV variables.

Investing more on Flight Test Actions Marketing would return more knowledge on Flight Test activity and all the benefits that Air Force would have. A better image increases both Good Will from authorities and a larger set of people for selection, improving flight test student crews.

Related to the number of failing students (CEV), provide to make this number smaller would return on more graduated flight test crews, and more available flight crews even if graduation had to be delayed for six or twelve months.

Investing on PLAMENS was not considered a good strategy on the present conditions, once the larger the number of Flight Tests researchers, the smaller the number of Flight Test executing its main mission, what would begin a Feedback Loop that deteriorates IPEV productivity on Flight Tests performed. 


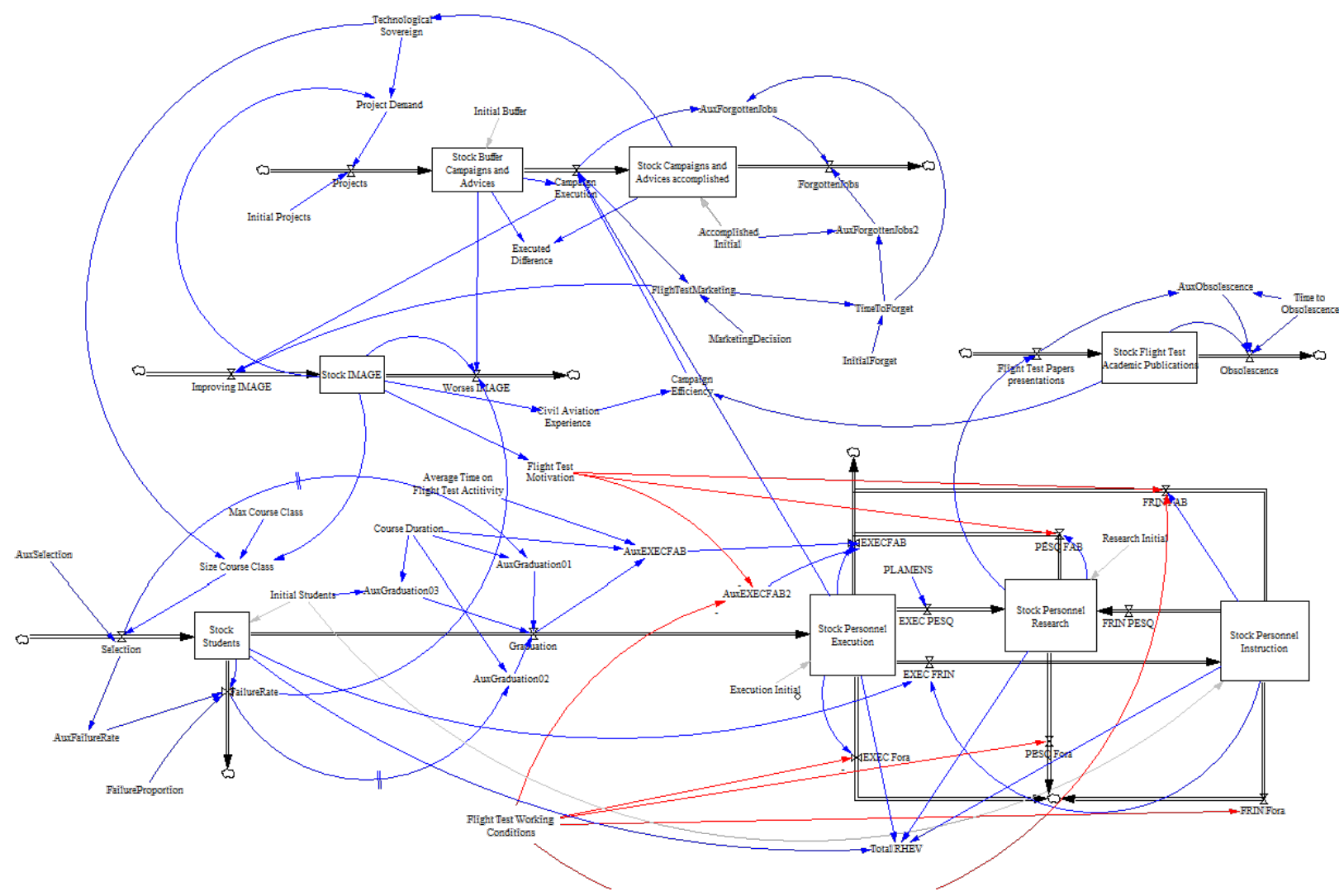

Fig 6. System Dynamics Model
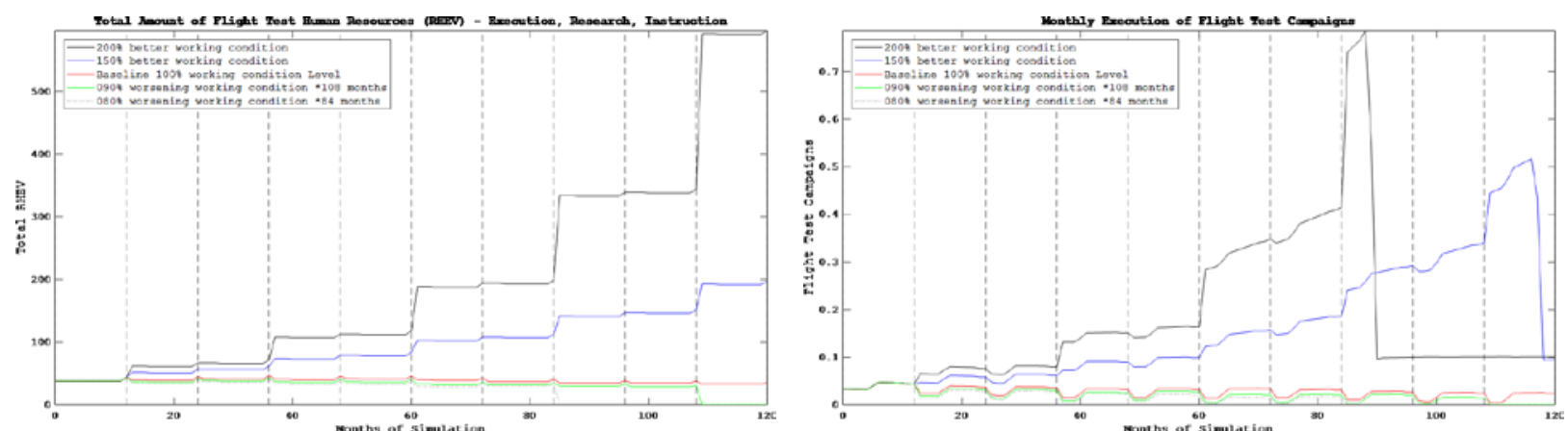

Fig 7. Graphs for 10 years SDM simulation 


\section{Conclusions}

The final products of Case Study showed the effectiveness of the proposed GMB Script for a more effective System Dynamics Model development.

The GMB Script allowed to consider opinions, points of view and mental models from all levels of Stakeholders and a good support on the Flight Test environment for Brazilian Air Force.

Preparation based on questionnaires and CogMaps helped Stakeholders to consider new options and new connections on their mental constructs, what permitted to a more detailed and objective System Dynamics Mental Map.

The graphical representation exposed the discussion collectively and permitted that all stakeholders on same level could express their ideas, as well as fomented new insights, once one was able to understand other's structured point of view on drawn maps.

Separation of stakeholders by level of power also showed a good return and transform the workshop for operational level stakeholders to an individualized interview increased commitment and willingness from higher authorities involved on process since beginning.

Using the loops from CogMaps also brought insights to probable feedbacks and balance loops system dynamics models.

Using GMB technique to elicit the structure of career flow also helped on insights related to same feedbacks present on real system.

All morphological analysis that could be performed on CogMaps and SDMM also made possible to arrive on a better System Dynamics Model, on the sense that Stakeholders could easier recognize their own ideas on the model and would be more convinced and committed to results presented.

For detailed models, variables used and results, refers to Author's Master's Degree Dissertation, reference [24] of this paper.

\section{Future Works}

Case Study could be improved using same procedure but covering other areas.

Influence of Aircraft Fleet available, procedures and involvement of maintenance are also very important matters to be included.

Feedbacks about money and financial issues may also be of interest and would show feedback loops that could define strategies even more reliable.

GMB Script could also be tested using Value Focused Thinking Approach (VFT) as a triggering initial mechanism, together with the questionnaires. Also, Value Focused Brainstorming could be included on Workshop phase.

\section{REFERENCES}

[1] J. W. Forrester. Industrial dynamics: a major breakthrough for decision makers. Harvard Business Review, v. 36, n. 4, 1958, pp. 37-66.

[2] J. Rosenhead, J. Mingers. Rational Analysis for a Problematic World: Problem Structuring Methods for Complexity, Uncertainty and Conflict, $2^{\text {nd }}$ edition, Chichester. John Wiley and Sons. 2001. 366p.

[3] D.F. Andersen, G. Richardson, J.A.M. Vennix. Group Model Building: adding more Science to the craft. System Dynamics Review v 13, issue 2. Summer 1997. pp. 187-201.

[4] P. Hovmand. Community Based System Dynamics. Springer, 2014. 104p.

[5] D.F Andersen. G. Richardson. Scripts for group model building. System Dynamics Review v 13, issue 2. Summer 1997. pp. 107129.

[6] E.A.J.A. Rouwette. J.A.M. Vennix. T, Mullekom. Group Model Building effectiveness: a review of assessment studies. System Dynamics Review v 18. 2002. pp. 5-45.

[7] R. J. Scott. R. Y. Cavana. D. Cameron. Recent evidence on the effectiveness of group model building. European Journal of Operational Research. V.249. pp. 908-918. 2016.

[8] A.C.J. Lucena. C.S.S.C. Lucena. L.M.S. Urbina. Ensaios em Voo no Brasil: a Geração de uma Competência Essencial. Anais do $8^{\circ}$ Simpósio de Segurança de Voo - SSV, 2015. Available at < http://ssv.ipev.cta.br/ssv-apresentacoes/2015/Apresentações/SSV 2015 S3A1 - Ensaios em Voo no Brasil.pdf>. Access on 01MAY2018.

[9] F. Ackermann. C. Eden. Strategic Management of Stakeholders: Theory and Practice. Long Range Planning. International Journal of Strategic Management, Vol 44, Issue 3, 2011, pp. 179-196.

[10] C. Eden. F. Ackermann. 2001. SODA - The Principles. In: Rosenhead, J., Mingers, J. (Eds.), Rational Analysis for a Problematic World Revisited: Problem Structuring Methods for Complexity $2^{\text {nd }}$ edition, Chichester. John Wiley and Sons, pp. 2141

[11] I. Georgiou. SODA - Basic Analysis of Complexity. 2006. Available at <http://slideplayer.com/slide/7832618/> Access on 08MAY2018.

[12] F. Ackermann. C. Eden. S. Cropper. Getting Started with Cognitive Mapping. 7th Young OR Conference. 1992.

[13] J. D. Sterman. Business dynamics: systems thinking and modeling for a complex world. Cambridge: Irwin McGraw-Hill, 2000, 982 p.

[14] I. Georgiou, 2018. Cognitive Mapping and Strategic Options Development and Analysis (SODA). Notas de aula, PO-211, Métodos de Estruturação de Problemas, ITA.

[15] F. Ackermann, C. Eden, 2010. Strategic Options Development and Analysis. IN: M. Reynolds, S. Holwell; System approaches to managing change: a practical guide. London: Springer, 2010. P.135-190

[16] R. V. V. Vidal, 2006. Operational Research: A Multidisciplinary Field. Pesquisa Operacional, v.26, n.1, p.69-90, Janeiro a Abril de 2006

[17] F. Ackermann, 2012. Problem structuring methods 'in the Dock': Arguing the case for Soft OR. European Journal of Operational Research. Volume 219, Issue 3, 16 June 2012, pp. 652-658.

[18] G.A. Kelly, 1955. The Psychology of Personal Constructs. 2nd edn. Routledge: London.

[19] J. W. Forrester, 1961. Industrial dynamics. New York: John Wiley and Sons.

[20] D.C. Lane, 2007. The Power and the Bond between Cause and Effect: Jay Wray Forrester and the Field of System Dynamics. System Dynamics Review 23 (2-3). 2007, pp. 95-118.

[21] D.H. Meadows, 2009. Thinking in Systems: a primer. White River Junction, VT: Chelsea Green Publishing, 218 p

[22] J.D. Sterman, 2002. All models are wrong: reflections on becoming a systems scientist. System Dynamics Review 18.pp. 501-531.

[23] M. Kunc, 2018. OR Essentials, vol. System Dynamics - Soft and Hard Operational Research. Palgrave Macmillan UK. 484p. 
[24] A.C.J Lucena, 2018. Estruturação de um Modelo de Dinâmica de Sistemas com Group Model Building: um Estudo de Caso em Recursos Humanos do IPEV. 201 f. Dissertação de Mestrado em Engenharia Aeronáutica e Mecânica, Área de Gestão Tecnológica - Instituto Tecnológico de Aeronáutica, São José dos Campos. (http://www.bdita.bibl.ita.br/tesesdigitais/lista_resumo.php?num tese $=74510$ )
[25] J.M. Bryson, 2004. What to do when Stakeholders matter: stakeholder identification and analysis techniques. Public Management Review, Vol 6, Issue 1, 2004, pp. 21-53.

[26] R.L. Keeney, 1996. Value-Focused Thinking a Path to Creative Decisionmaking. Harvard University Press; Revised ed. February $1^{\text {st }}, 1996$.

[27] R.L. Keeney, 2012. Value Focused Brainstorming. Decision Analysis, Vol 9, No. 4, December 2012, pp. 303-313. 